\title{
PAARIST ASTRONOOMILISEST ARGIUSKUMUSEST
}

\author{
Andres Kuperjanov
}

\begin{abstract}
TEESID: Artiklis käsitletakse mitmeid tähistaevaga seonduvaid ütlusi ja arvamusi, mis rahvaastronoomia ja astronoomia seisukohalt ei pruugi tõesed olla. Suur Vanker on Ursa Majori heledamatest tähtedest tagaosa. Paljude maade rahvaastronoomia tunneb seda nt seitsme vennana, ingliskeelses maailmas seitse moodustavad heledat tähte kujundi, mida tuntakse nime all Big Dipper, kuid Vankri kujundis on oluline osa ka kaheksandal, natuke nõrgemal tähel Alcoril ja nii ka eesti rahvaastronoomias moodustab vankri kaheksa tähte. Samuti ei vasta tõele, et Plejaadides on seitse tähte, neid on kas kuus või parematel nägijatel kuni üheksa. Seega vaadeldakse ka kadunud Plejaadi fenomeni, mis on tuntud mitmete maade rahvaastronoomias. Sodiaagi 12 tähtkuju on samuti vaatluse all, algselt 12 tähtkujule leiutati Rooma ajal lisaks kolmeteistkümnes, samal ajal unustati täielikult Maokandja tähtkuju, kus Päike viibib üle kahe korra kauem kui praeguses Skorpionis.
\end{abstract}

MÄRKSÕNAD: rahvaastronoomia, Suur Vanker, Plejaadid, Sodiaak, astronoomia varane ajalugu

Kui „õiged tähtkujud“ veel loomata olid ja tähti taevas vaadati kui mingeid jumalate lambikesi või midagi muud sarnast, hakati neist ka juba ühtteist kokku luuletama ja mõndagi arvama. Varemalt on arutletud, kuidas võis toimuda tähtkujude väljakujunemine ja evolutsioon (nt Kuperjanov 2005), kuidas arenesid mitmesugused piltlikud-literaarsed kujutlused antiikmaailmas (nt Müller 1978), üldisemalt (nt Allen 1963), balkani ja slaavi rahvastel (Mladenova 2006) ja ka Eestis (nt Kuperjanov 2003). Mitmete taevaste objektidega seonduvate motiivide levikut on oma andmebaasi alusel käsit- 
lenud Yuri Berezkin, kelle Suure Vankriga seonduvale artiklile käesolevas kogumikus viitan ka allpool seitsme venna kontekstis.

Paralleelselt klassikaliste tähtkujude evolutsiooniga on toimunud ka rahvapäraste tähtkujude areng, kuid erinevalt antiikpoeetide ja antiikmütoloogia uurimisest ei ole rahvapärase tähetundmise uurimine olnud varasematel aegadel, kui vastav traditsioon veel elas, üldse prestiižne. Näiteks 19. sajandi alguse saksa teadlane Karl Otfried Müller puudutab Orioni tähtkuju käsitledes kaasaegseid folklooriteateid vaid möödaminnes:

Aga vanad kreeklased ei uskunud kindlasti tema (Orioni) tegelikku ja personaalset olemasolu taevas, mitte rohkem kui meie maamehed, kui nad kutsuvad neid kolme tähte Kolmeks Pühaks Kuningaks [---]. (Müller 1978: 133-134)

Kui „päris astronoomiast“ tuntud Orionist võime leida käsitlusi mitmetest sadadest või isegi tuhandetest raamatutest, siis andmed kolmest pühast kuningast on sellega võrreldes praktiliselt olematud.

Kuid kindlasti on rahvapärane tähetundmine ehk etnoastronoomia olnud väga oluline järgnevalt käsitletavate argiuskumuste kujunemisel ja võimalik, et ka vastavad uskumused klassikalises mütoloogias pärinevad hoopiski varasemast rahvaastronoomiast, olles antiikpoeetide poolt ilustatud ja personifitseeritud. See omakorda peegeldub tagasi nn tavapäraste astronoomiliste arusaamadeni ja seda niivõrd sügavalt, et samad argiuskumused kuuluvad ka elukutseliste astronoomide käibetõdede hulka.

Selles artiklis vaatlen lähemalt kahte levinuimat argiuskumuste gruppi, mis põhinevad ilmselt arvude seitse ja tosin ilul ja uskumuslikul taustal: seitse tähte on seostunud Suure Vankri tähtkuju ja Plejaadide täheparvega ning kaksteist tähtkuju seostub sodiaagiga, saades pidevalt täiendavat toitu mitmesugustest esoteerilistest allikatest.

\section{SEITSE TÄHTE SUURES VANKRIS}

Kõigepealt alustame näitega populaarsest saatesarjast „Targem kui 5b“.

Neljanda klassi loodusõpetus: mitu tähte on Suure Vankri tähtkujus? Mängija pakkus, et kuus tähte. Õige oleks olnud seitse. Kuna pinginaaber Maarja vastas samuti valesti, lahkus Kadri saatest 10000 krooniga. (http://targem.elu24.ee/ ?id=108754)

Saatetegijate sõnul on vastuste kontrollimisel kasutatud lisaks kooliõpikutele ka tunnustatud teatmekirjandust (küsimused on saate jaoks koostanud Eesti Entsüklopeediakirjastus - http://www.ene.ee/uudis.php 19.09.2008), 
mille vastavad artiklid on kindlasti kirjutanud või vähemalt refereerinud elukutseline astronoom. Ja tõepoolest - ingliskeelses maailmas kujutatakse Suurt Vankrit kui seitsmest tähest koosnevat kulpi (Big Dipper), mitmetel teistel rahvastel moodustavad Suure Vankri põhikujundi seitse tähte, mis on kas seitse inimest, venda või muud tegelast. Seda teemat on pikemalt analüüsinud Yuri Berezkin käesolevas aastaraamatus ja seetõttu ma sellel siinkohal pikemalt ei peatu.

Tähtkuju kaheksas, väiksem täht on neis kujutlustes kõrvale jäetud. Kuid Eestis on 18. sajandi algul Salomo Heinrich Vestringi ülestähendatud Hunt Härja Kõrval üks vanimaid jäädvustatud tähenimesid.

Taewa Wanker oder Wagen am Himmel Ursa major, Hunt Härja körwal. Ein kleine Stern bey einem grösseren. (Vestring 1998: Täht)

Järgnev näide, peatükk III klassi lugemikust (Siim, Vallner 1967), on mõnevõrra toimetatud versioon Jakob Hurda „Eesti Astronomiast“ (Hurt 1899) pärinevast Suure Vankri loost. Alates 1913. aastal ilmunud Mihkel Kampmanni „Kooli lugemise raamatust“ on see lugu olnud pidevalt hariva tekstina kasutusel.

\section{HUNT HÄRJA KÕRVAL}

Eesti muinasjutt

Ennemuiste läks talumees, Peedu nimi, vankriga, mille ette härg oli rakendatud, läbi metsa. Korraga tuli hunt metsast ja kargas härja turja, et teda vankriaisade vahel ära murda. See oli aga seaduse vastu. Hunt tohtis küll loomi murda ja süüa, aga ei iialgi siis, kui loom parajasti töötab. Et hundid edaspidi niisugust kurja enam ei teeks, tõstis Vanaisa hoiatuseks Peedu ühes tema vankri ja härjaga, ühtlasi ka murdja hundi taevalaotusse. Hundi rakendas ta karistuseks härja kõrvale vankri ette, ka koormat vedama.

Et see nii on sündinud, näeme veel nüüdki igal selgel ööl Suure Vankri tähtedest taevas. Neli tähte, mis nelinurka on seatud, on neli vankriratast. Kolmest tähest vankri ees on esimene ais, tema järgmine on härg, kolmas kõige ees on peremees Peedu. Aga keskmise ehk härja kõrval on veel pisike täheke: see on hunt. Hunt ei taha koormat vedada ja kisub metsa poole. Sellest ongi siis tulnud, et Suure Vankri tähtkuju keskmine täht ehk härg on sirgjoonest kõrvale kistud ja metsa poole kaldub. (Siim, Vallner 1967: 111)

Kas me tahame või ei taha, eesti Suures Vankris saame paratamatult kokku kaheksa tähte. Aga kuidas on lood mujal? 
Suur Vanker on ilmselt laenatud tähtkujunimi. Vankrina on seda tähtkuju tuntud laialdaselt, nii Hiinas kui ka Babüloonia taevakaardi rekonstruktsioonides ja antiikmaailmas. Germaani vankrit omistatakse sageli Karl Suurele.

Karl Suure Vanker. Kujutatakse kolmehobusevankrina, kus hobused on kiirest jooksust vankri ees lehvikuna laiali ja keskmisel hobusel istub kutsar. Alcori ehk kaheksanda tähe enda kohta on teada veel mitmeid nimesid, näiteks kreeklastel oli ta rebane, kuid ladinakeelsena Eques Stellula, Inglismaal Jack on the Middle Horse, Saksamaal Holsteinis voorimees Hans Dümke. (Allen 1963: 446)

Üht-teist Suurest Vankrist võib täiendavalt lugeda ajakirjast Mäetagused (Kuperjanov 2010).

Nagu näeme, siis meie Suure Vankri suurel eeskujul, germaani rahvaste vankril on ka kaheksas täht ära märgitud ja esile tõstetud. Ja praeguses kontekstis julgen ma väita, et Suure Vankri seitse tähte on meie tingimustes levinud argiuskumus, tegelikult, kui me teemasse natukenegi süveneme, moodustub eesti Suur Vanker oma täielikus ilus kaheksast tähest. Siinkohal ei tahaks ma siiski astronoomidega pahandada, enamasti on ju kõik õige, Tõravere lipul on kenasti kaheksatäheline vanker suure kupli kohal, teatakse ka Hurda kirjapandud juttu hundist ja härjast, aga ikkagi juhtub aeg-ajalt, et väikese Alcori olemasolu unustatakse.

\section{SEITSE TÄHTE TAEVA SÕELAS}

Üldlevinud on arvamus, et Sõelas on seitse tähte. Niimoodi arvavad peaaegu kõik rahvad, kes elavad nendel aladel, kus see iseloomulik täheparv nähtav on. Antiikastronoomias oli Sõel algselt tuntud laevatähtedena, selle heliaakliline tõus tähistas kevadise laevatamise algust. Kuid pretsessiooni tõttu kadus Vana-Kreekas Sõela moodustava täheparve funktsioon navigatsioonihooaja algust tähistava märgina, seetõttu nimetasid kreeka poeedid selle täheparve Atlase ja Pleione seitsme tütre järgi Plejaadideks. Mõningate müütide järgi olevat Plejaadid muudetud lindudeks ja nad lendasid taevasse. Seetõttu on neid vahel tekstides nimetatud ka tuvideks.

Pseudo-Apollodorus „Bibliotheca“ (2. saj.):

Atlasele ja Okeanose tütrele Pleionele sündis seitse tütart, keda nimetati Plejaadideks ja kelle nimed on Alkyone, Merope, Kelaino (Celaeno, ka Calaeno), Elektra, Sterope (Asterope), Taygete, ja Maia. (Theoi Greek mythology: Pleiades) 


\begin{tabular}{|c|c|c|}
\hline $\operatorname{M\alpha 1\alpha }$ & Maia & Hea hoolitsev ema \\
\hline 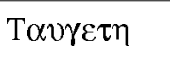 & Taygetê & Taygetuse mäe järgi \\
\hline $\begin{array}{l}\Sigma \tau \varepsilon \rho \circ \pi \eta \\
\text { А } \tau \varepsilon \rho \circ \pi \eta\end{array}$ & $\begin{array}{l}\text { Steropê } \\
\text { Asteropê }\end{array}$ & $\begin{array}{l}\text { Helkivanäoline } \\
\text { Tähenäoline }\end{array}$ \\
\hline 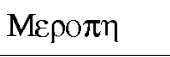 & Meropê & Sädelevanäoline \\
\hline $\mathrm{A} \lambda \kappa \cup 0 \vee \eta$ & Alkyonê & Tugev abiline \\
\hline $\mathrm{H} \lambda \varepsilon \kappa \tau \rho \eta$ & Êlektrê & Merevaik \\
\hline 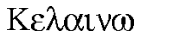 & Kelainô & Tume \\
\hline
\end{tabular}

Tabel 1. Plejaadide nimed

Üldjuhul omistatakse täheparve ümbernimetamist Hesiodesele umbes 2700 aastat tagasi. Kuivõrd siin võib olla seost kunagise rahvaastronoomiaga, on raske hinnata või arvata, kuid osa antiikalast võib kuuluda sellesse piirkonda, kus on tuntud motiiv Sõelast kui seitsmest noorest naisest või seitsmest õest. Etümoloogiliselt on täheparve nime seotud peamiselt kreeka sõnaga $\pi \lambda \varepsilon \sigma \sigma$ 'täis/palju', $\pi \lambda \varepsilon \imath \omega_{\nu}$ 'rohkus', kuid sellele on kõlalt lähedased ka $\pi \lambda \varepsilon \iota v$ 'purjetama' ning $\pi \varepsilon \lambda \varepsilon \imath \alpha \delta \varepsilon \sigma$ 'tuviparv'.

Pseudo-Hyginus „Astronomica“ (II saj.):

Meie kirjanikud kutsusid neid tähti Vergiliae (kevadised), sest nad tõusevad kevade järel. Nad leiavad praegugi rohkem tähelepanu kui teised, sest nende tõusmine on suve märk. (Theoi Greek mythology: Pleiades)

Siin on pretsessioon juba oma töö teinud ja kevadekuulutajatest on saanud suve märk. Ka on rooma mütoloogiasse imbunud Vergiliae - Plejaadide tähtkuju jumalannad. Tuntud on ka versioon Kevadised Neitsid.

Ka teiste maade rahvaastronoomias ollakse enamasti veendunud, et Sõelas on just seitse tähte. Tegelikkuses on Sõelas näha ainult kuus tähte ja kui peaks olema ideaalsed tingimused ja absoluutne nägemine, siis oleks tõenäoliselt nähtavad juba 8-9 tähte, niivõrd väikesed on nende nõrgemate tähtede heleduste erinevused. Väidetakse, et teleskoobieelse aja täpseima tulemuse saavutas 1579. aastal Michael Maestlin, keda tuntakse peamiselt Johannes Kepleri õpetajana, kes suutis joonistada enam-vähem täpselt Plejaadide skeemi 11 tähega. Seoses optiliste vaatlusvahendite kasutuselevõtuga kasvas täheparve tähtede arv veelgi ja üsna peagi kaardistati täheparv uuesti, nüüd on ka Atlas ja Pleione ise täheparve täisõiguslikud ja heledad liikmed. 1846. aastal avastas Tartu Tähetorni juhataja Johann 


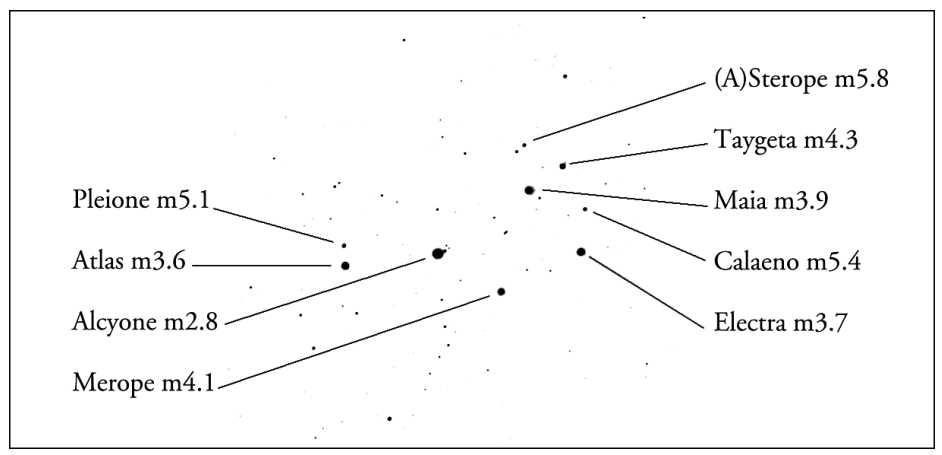

Nü̈̈disaegne kasutusel olevate Plejaadide nimede kaart, lisaks seitsmele Plejaadile on siin oma koha leidnud ka Atlas ja Pleione. Need üheksa tähte on oma heleduselt (ilma täiendavate optiliste abivahendite kasutamiseta) nähtavuse piirides.

Heinrich von Mädler täheparve kuuluvate tähtede omavahelise liikumise, mille keskmeks on suurem täheparv Alcyone lähedal. Tema tähesüsteemide teooria ilmus raamatus „Zentralsonne“.

Kuna seitsme tähe nägemisega on suuri raskusi, siis arvatakse, et seitsmes on kadunud, läinud kusagile mujale - enamasti Suurde Vankrisse. Tuntuimaks kadunud õeks on Elektra, kes häbenes Trooja lahingut ja muutus seetõttu nähtamatuks, ka olevat ta liikunud Suurde Vankrisse, temast olevat saanud Alcor. Peaaegu sama levinud on Merope kadumine, kes abiellus surelikuga ja muutus seetõttu piinlikkusest tuhmiks.

Pseudo-Hyginus „Astronomica“ (2. saj.):

Teiste õdede tõttu paigutati ka tema [Merope] tähtkujude hulka, aga kuna ta abiellus surelikuga, on tema täht tuhm. Teised räägivad, et Elektra ei ole nähtav, kuna Plejaadid on mõeldud tähtede ringtantsu juhtima, aga kui Trooja langes ja ta poja Dardanuse järglased allutati, lahkus ta leinas teistest Plejaadidest ja võttis omale koha kaarel, mida kutsuti Arktikaks. Oma pikaajalises leinas ilmub ta sealt, juuksed lahti, seetõttu nimetatakse teda komeediks. (Theoi Greek mythology: Pleiades)

Ovidius „Fasti“ ( 1. saj. eKr - 1. saj. pKr):

Räägitakse, et seitse, harilikult on neid kuus, seetõttu, et kuus neist läksid jumalate embusse (nagu nad räägivad, Sterope oli koos Marsiga (Ares), Alcyone ja sina, kaunis Celaeno, Neptuuniga (Poseidoniga), Maia, Electra, Taygete Jupiteriga (Zeusiga), Merope abiellus sinuga, surelik Sisyphus, ta 
kahetseb seda ja peidab end häbis üksindusse, või seetõttu, et Elektra ei suutnud välja kannatada Trooja langemist ja kattis oma silmad kätega. (Theoi Greek mythology: Pleiades)

Kui uskuda antiikpoeete, siis olid kreeka jumalad ühed ropud ja vägivaldsed tegelased, eesotsas nende peajumala Zeusiga, kes ilmselt üksinda oli vägistanud umbes poole Kreekas elavatest naistest. Ja nii juhtus ka Plejaadidega. Ainult surelikuga abiellunud Merope jäi jumalatest puutumata. Tuntuima kadunud plejaadi Elektra, Itaalia kuninga Corythuse naise, vägistas Zeus ja sellest sündis Dardanus, Trooja asutaja. Troojaga on seostatud ka teist Plejaadi Asteropet, kes olevat armunud Trooja kuninga poega - pärast Trooja langemist olevat Asterope hinge heitnud ja muutunud seetõttu kadunud Plejaadiks. Selle versiooni puhul kahtlustatakse, et võib olla tegemist ka mingi teise Asterope-nimelise tegelasega. Ka Taygete olevat sattunud Zeusi vägistamise ohvriks, sellest olevat sündinud ebaõnnega Lacedaimon, Sparta kuningas. Taygete peitis (Pseudo-Plutarchuse sõnutsi poos (Blunck 2010)) end Amyclaeuse mäel, mis tema mälestuseks nimetati Taygetuse mäeks. Theon Noorem 4. sajandist aga kirjutab, et kadunud olevat noorem õde Celaeno, kes olevat kas andnud poole oma hiilgusest Taygetele või olevat teda tabanud välk ja seepeale olevat ta tuhmunud (Andrews 2004: 72-73).

Seega ei ole tegelikult mingit ühtset seisukohta kadunud Plejaadi suhtes, seitsmest õest viie kohta on tuntud erinevaid kadumise põhjuseid:

1) Elektra lahkus, muutus Alcoriks, komeediks Trooja hävingu tõttu;

2) Merope tuhmus surelikuga abielu tõttu;

3) Asterope suri kurvastusest Trooja hävingu tõttu;

4) Taygete peitis/poos end Zeusi tagakiusamise eest;

5) Celaeno andis oma hiilguse Taygetele või tuhmus välgutabamusest.

Kadunud Plejaadi on tuntud mujalgi. Näiteks Austraalia põliselanike arvates oli kadunud õde kõige noorem (Andrews 2004). Tšerokeede müüdi järgi olevat Sõelaks taevasse tõusnud seitse poissi, kuid ühe ema olevat pika teibaga oma poega päästa üritanud, see kukkus alla, sügavale maa sisse, kus ema käis teda pikalt leinamas. Pisaratest kasvas suur puu, seetõttu kasvavad puud kõrgele tähtede suunas ja Sõela seitsmes täht on nõrgem kui teised (Mooney 1970). Kirgiiside pärimuses olevat lehmad tallanud puruks suure rohelise putuka, kelle tükid jäänud taevasse, üks tükk aga lennanud Suurde Vankrisse (Tallqvist 1942).

Sõela ja Suure Vankri seostamise tõenäoline põhjus on nende tähtede paigutuse mõningane visuaalne sarnasus. Väidetavalt olevat seda teadvustatud juba Muinas-Egiptuses. Üks huvitav seos lähtub ka mitmete müto- 
loogiliste tegelaste segamisest: Boiootia kütt Orion jahtis Khiosest pärit Meropet, Oenopioni tütart, keda on peetud varasemas mütoloogias mesilaste kaitsjaks, hiljem meesööjaks ja kaudsemalt seostatud ka mesilasema Melissaga ja kes ilmus sageli (ema)karu kujul. Tema karukuju on ühendatud jumalanna Artemisega. Artemisele pühendatud Brauronia-pidustustel riietati noori tüdrukuid kollastesse krookusekarva riietesse, ohverdati kits ja riituse käigus pidid nad imiteerima karusid. Selline sümboolne karuohverdus Arkteia oli selles Atika linnas Brauronis abielueelse rituaalina kohustuslik (Smith 1870). Emakaru aga on Suur Vanker. Ja nagu tolleaegsele mütoloogiale kombeks, otse loomulikult vägistas Orion selle Merope. Ja vastavalt sellele loole on sageli ka Plejaadide Merope nime tõlgendatud sädelevanäolise asemel meenäoliseks ning niimoodi on saanud alguse üks levinumaid astraalmüüte Plejaade jälitavast Orionist. Tõsi küll, Plejaade järgivast Orionist olevat kirjutanud juba Hesiodes, kuid algselt ei olnud see midagi muud kui kujundlik väljend tähtede asendi ja liikumissuuna kohta (Müller 1978).

\section{KAKSTEIST TÄHTKUJU (SODIAAK)}

Arvatakse, et Mesopotaamias jagati ekliptika tinglikult 12 võrdseks osaks juba enam kui 4000 aastat tagasi. Ühtlasi on ka osa autoreid arvanud, et tolleaegses astronoomias ei olnud ajamääramises olulised mitte konkreetselt tähtkujud, vaid nende heledamad tähed, mis on ka loogiline, sest selliselt on võimalik taevakehade liikumist märksa täpsemalt määratleda. Kui ekliptika tasandis oli babüloonlastel tuntud 12 tähtkuju, siis Kuu liikumise arvestamisel olid olulised veel täiendavalt kuus tähte/tähtkuju.

Kreeka astronoomid võtsid algselt üle Babüloonia sodiaagi 12 tähtkuju, mõningate ümbernimetamistega. Hipparchos (Hipparchus) fikseeris sodiaagi abil taevaste koordinaatide võrgu 2. sajandil eKr. Umbes samast ajajärgust hakkavad tekkima esimesed vihjed sodiaagi 13-ndale ning esimesele elutule tähtkujule - Kaaludele.

Kaalude tähtkuju tekke võimalikuks põhjuseks peetakse peamiselt akkadikeelse sõna zibanitu 'skorpion' kõlalist sarnasust araabiakeelse sõnaga zubānā 'kaal'. Araabia keel oli sellel ajal peamiseks vahenduskeeleks eri kultuuriregioonide vahel, nii on täiesti võimalik uue nime teke poolkeelsete kultuurivahendajate tõttu. Kreekas, Hesiodesel, kes elas umbes samal ajal, kui Babüloonias kujunes välja sodiaak (umbes 2800 aastat tagasi), oli Skorpion väga suur elukas, kelle ülesandeks oli Orion hävitada. Kaalud ilmuvad taevasse palju hiljem. 
Pseudo-Hyginus „Astronomica“ (2. saj.):

Skorpion. See tähtkuju on jagatud oma suurte sõrgade pärast kaheks osaks. Ühte osa kutsuvad meie kirjutajad Kaalud (Libra). (Theoi Greek mythology: Scorpius)

\begin{tabular}{|c|c|c|c|c|c|}
\hline Ajavahemik & \multicolumn{2}{|c|}{ Tegelik tähtkuju } & Ligikaudne & ajavahemiku astronoo- & tähemärgi \\
\hline $18.12-19.01$ & Ambur & Sagittarius & 32 päeva & ব/6 (Sgr/Cap) & 22.12 \\
\hline $19.01-15.02$ & Kaljukits & Capricornus & 28 päeva & $\succsim / \approx(\mathrm{Cap} / \mathrm{Aqr})$ & 20.01 \\
\hline $16.02-11.03$ & Veevalaja & Aquarius & 24 päeva & $\approx /)($ Aqr/Psc $)$ & 18.2 .10 \\
\hline $12.03-18.04$ & Kalad & Pisces & 38 päeva & H/r (Psc/Ari) & 20.03 \\
\hline $18.04-13.05$ & Jäär & Aries & 25 päeva & $\Upsilon / ठ($ Ari/Tau $)$ & 20.04 \\
\hline $14.05-20.06$ & Sõnn & Taurus & 38 päeva & ૪/П $\quad(\mathrm{Tau} / \mathrm{Gem})$ & 21.05 \\
\hline $21.06-20.07$ & Kaksikud & Gemini & 30 päeva & e $(\mathrm{Cnc})$ & 21.06 \\
\hline $20.07-10.08$ & Vähk & Cancer & 22 päeva & e/ת (Cnc/Leo) & 23.07 \\
\hline $10.08-16.09$ & Lõvi & Leo & 38 päeva & 凡/m及 (Leo/Vir) & 23.08 \\
\hline $16.09-30.10$ & Neitsi & Virgo & 45 päeva & m/ $/ \underline{\Omega} / m_{1}(\operatorname{Vir} / \mathrm{Lib} / \mathrm{Sco})$ & $23.09 / 23.10$ \\
\hline $31.10-22.11$ & Kaalud & Libra & 23 päeva & $\mathrm{m} / x(\mathrm{Sco} / \mathrm{Sgr})$ & 22.11 \\
\hline $23.11-29.11$ & Skorpion & Scorpius & 7 päeva & (Sgr) & - \\
\hline $30.11-17.12$ & Maokandja & Ophiuchus & 18 päeva & $x \quad(\operatorname{Sgr})$ & - \\
\hline
\end{tabular}

Tabel 2. Ekliptika tähtkujud ja Päikese vastavas tähtkujus viibimise aeg

Tabelist on selgelt näha, et nn päikesemärgid on tugevalt üldistatud ja kattuvad ainult osaliselt Päikese vastavas tähtkujus viibimise ajaga. Suurte sõrgadega Skorpion (Kaalud + Skorpion) oleks täiesti korralik praktiliselt ühe kuu pikkune tähtkuju. Väljakujunenud süsteemi kohaselt jääb aga Päikese viibimine Skorpionis oluliselt lühemaajaliseks kui sodiaagist välja arvatud Maokandjas.

Eudoxus (4. saj. eKr) ja Aratus (3. saj. eKr - suur koletis Skorpion, sõrad on eraldi märgitud) ei ole oma tekstides Kaalude tähtkujust midagi rääkinud, kuid umbes sellel ajal hakkab Kaalude tähtkuju tasapisi ilmuma. Kuna tolleaegne kultuurivahendus toimus araabia keele kaudu, siis on üsnagi võimalik, et põhjuseks on eespool mainitud sõnade sarnasus. Hipparchosel Nikaiast ( 130 . aastast eKr) olid tuntud juba mõlemad Skorpioni tähtkuju kujutamise võimalused, algselt kasutas ta siiski Skorpioni sõrgi, kuid lõpuks on tal ka Kaalud, Zygos. Hypsicles Aleksandriast kirjutas juba oma töös „Anaphoricos“ (150. aastal eKr), et Kaalud tõusevad 38;20, Skorpion 35, Ambur 31;40 (numbrid tähendavad tema poolt sektoriteks jaotatud ekliptika koordinaate (Irby-Massie \& Keyser 2002)). Esimesena 


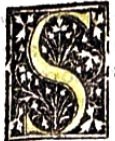

Corpii prior pars quę Cbele dicitur ita premit ab equinoctiali circulo:ut eum fuftinere uideat. Iple auté pedibus opbiulci de quo fupra diximus fub/ ditus extrema cauda circulü byemalë contingere uidet́. Neç longe eft ab co qư pro boltia centau's rus ferre profpicit. Occidit aute $e$ indinato capite:exorit erect? a chelis. Hic babet ftellas in bis quę cbele dicunt in unaquaç earum binas:ex quibus primę funt clariores. Pręterea babet in fronte ftellas tres: quarü media elt clariffima,Interfcapilio tres. In uentre duas. In cauda quinq3. In acumine iṕpo quo percutere exiftimat duas, Omnino ftellarü,xix.

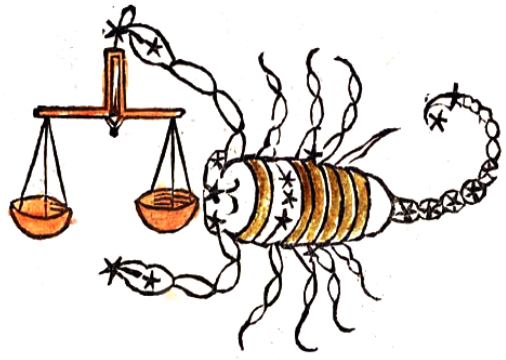

Scorpius
Hyginus, Poeticon

Astronomicon. Scorpius, Libra. Linda Hall Library of

Science, Engineering and

Technology

http://www.lindahall.org /

services / digital / ebooks /

hyginus / hyginus77.shtml.

kasutas oma töös järjekindlalt Kaalude tähtkuju Kreeka astronoom Geminos (umbes aastal $100 \mathrm{eKr}$ ). Arvatavasti suuresti Hipparcosele tuginedes koostas Claudios Ptolemaios II sajandil oma teose "Syntaxis“ („Almagest“), mis väidetavalt esmakordselt fikseeris täpselt antiikmaailma 48 tähtkuju. Kuid selles raamatus kasutas Ptolemaios valdavalt Skorpioni sõrgasid, Kaalud olevat tal vaid ühes kohas Kaldea Merkuuri-vaatlusi kirjeldavas tekstis ja läbivalt ainult tabelites (Evans, Berggren 2006: 117). Kuid ikkagi loetakse, et „Almagest“ oli just see teos, mis Araabia astronoomia kaudu fikseeris lõplikult Rooma astroloogidele meelepärase Kaalude tähtkuju, muutes sellega astroloogilised märgid suuremaks fiktsiooniks, kui nad olid seda enne.

Sellel ajajärgul esinesid sodiaagi mõlemad versioonid, nii Kaaludega (nt Farnese Atlase gloobusel (Schaeffer 2005)) kui ka ilma. Viimase näiteks võiks tuua Ptolemaiosega samast perioodist ja samast kohast, Aleksandriast pärineva nn Mainzi gloobuse (Mainz Globe). See on Mainzis RoomaGermaani muuseumis säilitatav pronkskera, millel on suure täpsusega kujutatud 48 klassikalist tähtkuju. Seda kera kasutati päikesekella gnoomoni tipuna. Sarnaste gloobuste kasutamist on märkinud Cicero, viidates Sculpicius Gallusele, kelle väitel kasutas tähegloobust Eudoxus ja ilmselt ka Thales (Kidd 2004). 
Taevagloobuste esmavalmistamist omistataksegi Thalesele Mileetosest. Selliseid gloobuseid on seni teada ainult kolm. Vanim neist, nn Kugeli gloobus on dateeritud vahemikku 300 kuni 100 aastat enne praegust ajaarvamist. See on väike 6,3-sentimeetrise läbimõõduga hõbekera, mida säilitatakse J. Kugeli antiigikaleriis Prantsusmaal, kuhu ta jõudis 1996. aastal. Arvatakse, et gloobuse algne valmistaja ei olnud astronoomias eriti tugev, kuna see ei järgi täpselt Hipparchose kehtestatud Kreeka-Rooma astronoomia norme, osa tähtkujusid on valesti paigutatud, vale suurusega ja isegi Kaalude tähtkuju ei ole Kugeli gloobusel kujutatud. Tunduvalt hilisem (150.-220. a.) Mainzi gloobus on oluliselt täpsem, kuid ka sellel on ainult suurte sõrgadega Skorpion. Nagu eelnevalt sai juba märgitud, siis samast ajavahemikust pärineva Farnese Atlase suurel gloobusel on see viga juba parandatud ning klassikaline Rooma sodiaak on välja kujune-

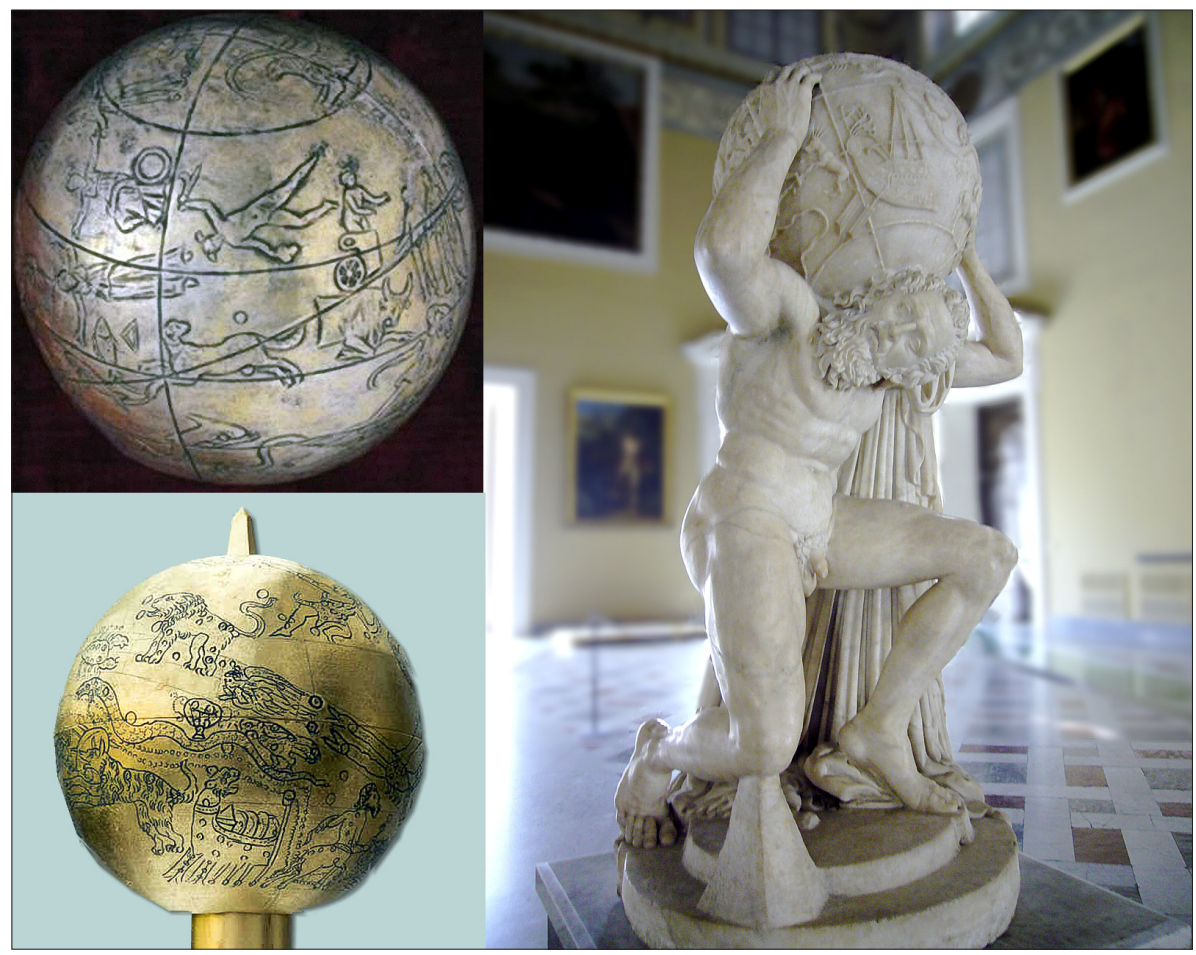

Vasakul üleval on Kugeli gloobus, all Mainzi gloobus. Nendel puudub Kaalude tähtkuju, alumisel, Mainzi gloobusel, paistavad paremal keskel Skorpioni suured sõrad, mis ulatuvad Neitsi tähtkujuni. Mainzi gloobusega samast ajast pärineval Farnese Atlase (paremal) taevamunal on Kaalud juba olemas. 


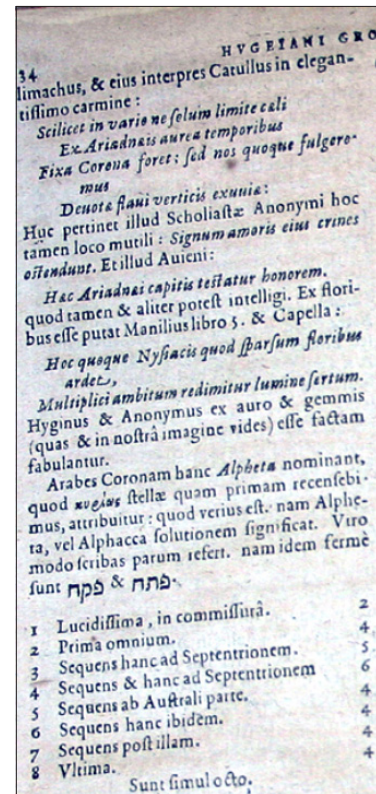

Prima ftclla magni nominis ct, ss. Alpheta, \& Malfelcare, \& Munir Arabibus appellatur, de quibus vide $S$ caligeri iudicium, qui $\alpha$ quare tum nomen Aclilufchemalicx Arabica Mapp protulit. Stella haceo in loco eft, vbi Corona colligatur. Solebant enim tzniis Coronas colligare, ita ve pars extra coronam penderet. Eas fáfiolas, $\lambda$ nurioxys rocabant. clegantem in imagine exManulcripto catita. Malè itaque faciunt qui Gnoffiam hanc, fiue Ariadneam Coronam, fine vllá commiffurà pingunt. Hyginus \& cum fecutus Anonymus nouem ftellas collocant, nifi in numeris crratum: Quod dici poff

primeret Faft. II . ignes:

Avire per fellas nuve mitat illa nousen.

Quod verò tres efle aiunt cxteris clariores fal.

fum, cum vna tantum fit fecunda magaitudi-

nis, tertix nulla, quart $x$ quatuor.

\section{TtT NOTE}

OPHIVCHYS CVM SERPENTE,

SCORPIVS CVM CHELIS.

Ophiuchus capite caput Nixicontingens fer. pente circumplicatur, qui cum medium cie. pente circumer per clunes tranfiens ad Aquila. gensa dextra per clunes finifta porrectus apud Coro vfque erigitur, a tinitua porrecus apud Coto. nam caput crigit: Ita vt ftella, qux in ment Coronam fermè attingat Germanicus:

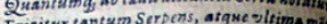
Erigitar tantam Sorpchs, afque virima mi Stcila, fub ativerea fuiger crinira Corend Sub pede finiftro Ophiuchi pectus eft Scorp nam quod Aratus rtrunq. pedem nominat, $e$ ¿xveg'tong", \& quod de oculo dicit nō omair

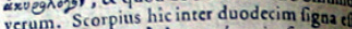

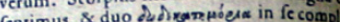
eptimus, sulo dicitur. Sed

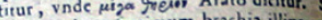
doheanuever icptimum brachia ilins com. plectuntur, qux Graxis zedaydicuitur. octaum corpus ipfius Scorpij. Habent Scorpii, it \& Cancri, prxter pedes fenos, rel (vt alii) octono Cancri, prxter peda, 8 in is vngulas biparita. duo quaf brachia, o in ism (volas Plinim) for Has Barbati graftas, Latimi (ve Plinias) ferf. culas, Graci $x$ tàs vocant. Ethoc pactos pius duas explet Zodiaci partes. Vade Germa. nicus:

Scorpios bine duplo, qvàm cutera, po fidet nh. Siders, fer Chelargominate lamine fflede

\section{Siderd,per
Ex Ouidius:}

Porrigit in ßatin w figsoril mombra dxera. Auetor carminis de Cyn:

Vyum auems divplici fellatum fidere oid: Scerpius, alternis clarum fuga: Oriexa.

Leorpias, alir vi fingula dedecatemotia fo Latini tamen, vi tingula dedccatcmora te gulis fignis conucnisent, Chclas Libram ra runt: $\alpha$ quia ca ia partécrifa elt, cam Czéa fecrarunt, \& Augufto. Hinc Virgilius fecrarunt, \& Auguto. Hiac Vaghas

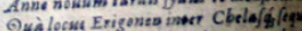

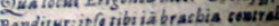
Panditur
Scorfiew.

\section{Scerpiw.}

Quo in loco non dicit eafdem effe Chela

Librâ, fed Libram ob Cxfaris hoaa

ter Scorpium \&. Virginem locatam oo

Scorpij brachiis. In Catalcetis babes I

ram quam Cajar kabef. Demeab

quod ait conucait cum illo loco in B

$$
\text { iscipient magniprocto }
$$

quod in $\mathrm{Cx}$ farum gratian diaum

uius. Huc quoque pertinere videt nilius librâ horofcopante natos iufí Imperatores, \& Libra pro regione Imperaters sium, Librahacfo affignatimperium. Libra hxce Virginis, ante Scorpionis brach
tracta cfe dixi. Ab rao laqeat
ARATESTI HANTONENA

OPHIVCHVS, ANGVIS, SCORPIVS.

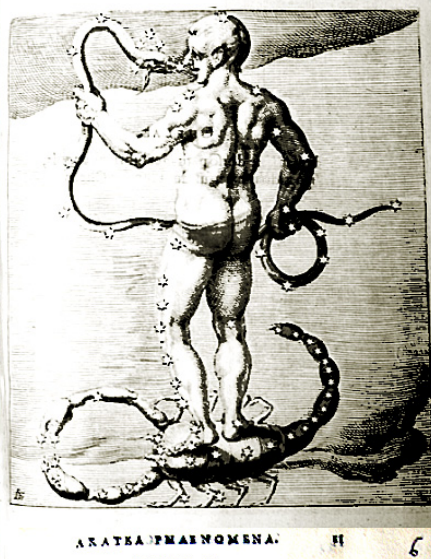

CHEL, E.

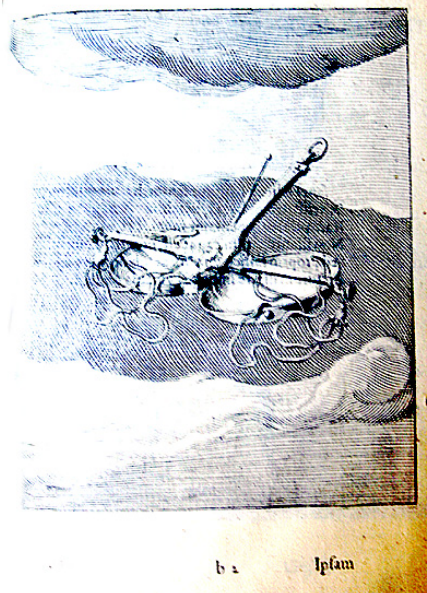

Hugo Grotiuse Skorpion ja sõrgadeks nimetatud Kaalud.

nud. Arvatavasti on olnud ka neljas Rooma-aegne gloobus, mis on sõdades kusagile kadunud, mida kirjeldas Jena klassikalise arheoloogia professor Rudolph Gaedechens 1862. aastal ilmunud kataloogis „Die Antiken des fürstlich Waldeckischen Museum zu Arolsen“, peatükis „Bildwerke in Stein“. Sellel ilmselt natuke hilisemal gloobusel oli samuti Kaalude tähtkuju olemas. 
Mis puutub Claudios Ptolemaios teosesse „Syntaxis“, siis see on tuntud vaid mitmeid sajandeid hilisema araabiakeelse koopia „al-kitabu-l-mijisti“ ehk lühidalt „Almagest“ kaudu. Paraku on seda fakti küll teadvustatud, aga enamasti ei ole sellega üldise astronoomia ajaloo ja tähtkujude kujunemise seisukohalt arvestatud.

Kuna tegemist on hilisema araabiakeelse koopiaga ja lisatud oli ka tähekataloog, siis avastasid hilisemad uurijad, et „Almagesti“ tabelid ei sobi Aleksandrias mõõdetavate koordinaatidega. Juba 16. sajandil tekkisid sellised kahtlused tuntud Taani astronoomil Tycho Brachel. 1977. aastal süüdistab Robert Russell Newton kuningas Ptolemaiost teaduslikus kuriteos paar sajandit varasema, Hipparchose kadunud kataloogi andmete varguses. 1989. on kolm Moskva meest viinud läbi põhjalikud võrdlused ja avaldanud artikli „When was Ptolemy's Star Catalogue in 'Almagest' Compiled in Reality? Statistical Analysis“ (Fomenko, Kalashnikov, Nosovsky 1989). Selgus, et statistilised rehkendused andsid kataloogi vanuseks vahemiku 600-1300 aastat, seega on tegemist märksa hilisema Araabia kataloogiga. Sellele lähim on al-Sufi kataloog, kus pikkuskraadid erinevad 12 kraadi 42 minutit. Abd al-Rahman al-Sufi (läänemaailmas ka Azophi) oli Pärsia astronoom, kelle raamat kinnistähtedest, mis ilmus tõenäoliselt 964. aastal, on üks Araabia astronoomia alustalasid ja selles seondatakse kreeka ja araabia astronüüme. Teda on peetud sageli ka Ptolemaiose tõlkijaks.

Ehkki Ptolemaiose raamat sai Araabia astroloogia/astronoomia aluseks ja Kaalude tähtkuju muutus nomenklatuurseks (ehkki eespool sai märgitud, et tõenäoliselt ilmselt Ptolemaios ise Kaalude tähtkuju ei kasutanud), säilitasid Kaalude tähtkuju heledamad tähed $\alpha$ Librae ja $\beta$ Librae oma Skorpionile viitavad nimed Zubenelgenubi ('lõunapoolne sõrg') ja Zubeneschamali ('põhjapoolne sõrg').

On väidetud, et Kaalude tähtkuju seadustati Julius Caesari poolt käskkirjaga, kuna see olevat sobiv tasakaalukusele viitav märk, ning ühtlasi olid need tähed ka parasjagu tolleaegse sügispunkti lähedal. Üsnagi sage on väide, et Kaalude tähtkuju tekkimisel oli oma osa kalendrireformil:

Skylore and Literature. Originally comprised the claws of the Scorpion, but was detached from Scorpius by the Romans to represent the vernal equinox. Has also been associated with the scales held by the goddess of justice. It was added by Julius Ceaser at the time of the establishment of the Julian calandar. (History of Science: Libra)

Euroopas ei võetud siiski Kaalude tähtkuju kohe õhinal omaks. Näiteks on teada, et karolingide renessansi perioodist 9.-10. sajandil pärineb selline Aratusele tuginev taevakaart, kus Kaalud puuduvad, aga Skorpion on 


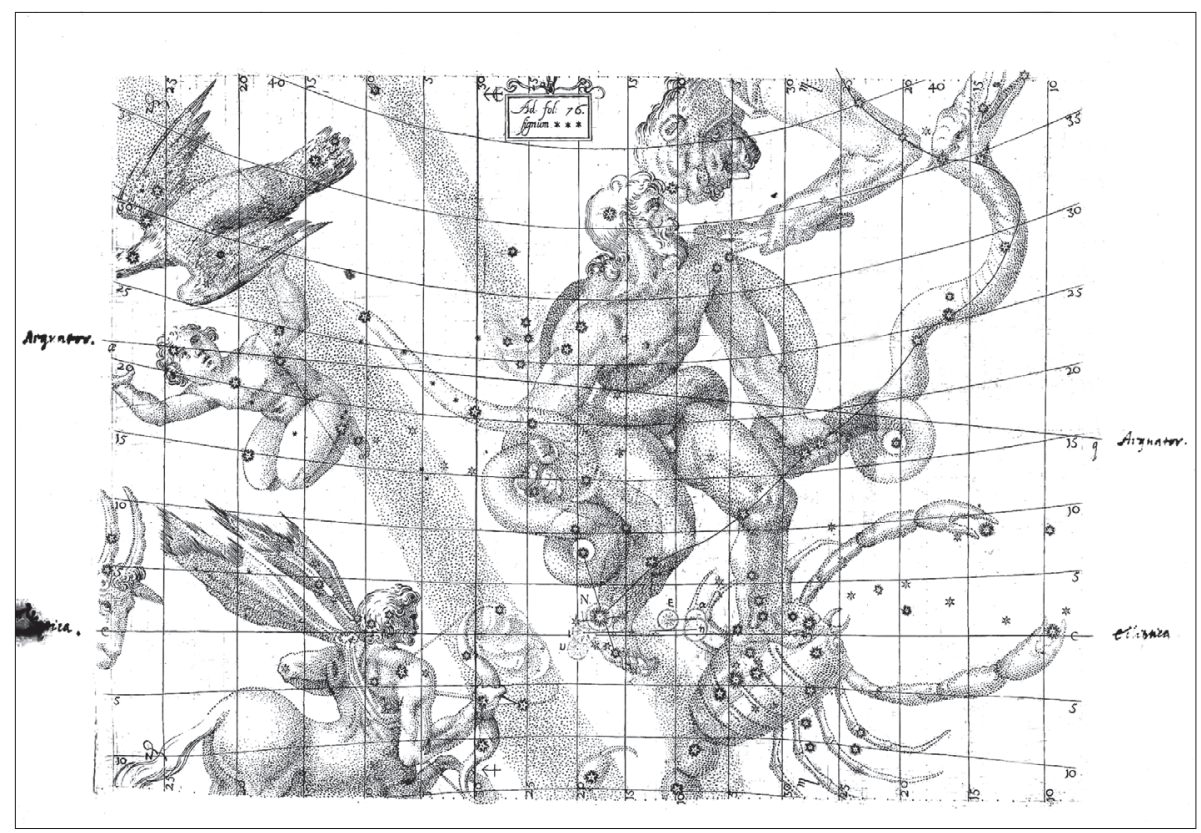

Kepleri tähekaart suuresõralise skorpioniga. WINTHROP COLLECTION, De Stella Nova in Pede Serpentarii (1606) by Johannes Kepler. http://www.nysoclib.org / collections / winthrop/kepler_johannes.html.

Rooma kaardi kohaselt lühikeste sõrgadega ja suuruse puudujäägi kompenseerib Skorpioni eriti pikk ja sirge saba. Selline kaart on leitud manuskriptist „Codex Vaticanus graecus 1087“ (fol. 310v), mis väidetakse olevat 15. sajandi Bütsantsi koopia 9. sajandi originaalist (Studies of Occidental Constellations and Star Names to the Classical Period).

Aastal 1600 kirjutab Hugo Grotius Hyginusele tuginedes, et Skorpioni ja Neitsi vahelisi tähti, endisi Skorpioni sõrgu, hakatud Caesari auks Kaalude tähtkujuks (Librae) kutsuma. Samas on tal eraldi kujutatud Kaalud, mille kohta ta kasutab nimetust Chelae 'sõrad' (Grotius 1600). Kuid ega sel ajal veel ilmselt Kaalude tähtkuju kõige tõsisemalt ei võetudki. Üks hilisemaid tähekaarte, kus Skorpionil on veel ausad sõrad, on 1606. aastal Prahas avaldatud Johannes Kepleri „De Stella Nova“.

Miks aga Maokandja ei sobinud roomlaste arvates nende sodiaaki?

Päikese viibimine suurte sõrgadega Skorpioni tähtkujus vastab parasjagu ühe kalendrikuu pikkusele ajavahemikule, kuid siiski otsustati täht- 
kuju jagada. Probleemiks võis olla, et kui enamasti on igas sodiaagitähtkujus üks selgemalt eristuv grupp, siis Skorpionis oleks neid kaks, kuid samas võimaldab sellise kahe heleda reepertähekomplekti olemasolu teostada märksa täpsemaid kalendaarseid mõõdistusi. Kuigi on arvatud, et Hipparchose aegadel võis Kaalude ja Jäära tähtkuju abil ühe mõõtmisega määratleda väga olulisi astronoomilisi hetki, võrdpäevsusi (Waerden 1974), ning sügispunktina määratlemiseks sobis väike tähtedegrupp natuke paremini astroloogilistesse kirjeldustesse ja tabelitesse kui suure Skorpioni sõrad, ehkki sõrad olid selles suures tähtkujus täpselt piiritletud ja isegi eraldi nimetatud. Maokandja tähtkujus ei ole ekliptika piirkonnas eriti silmapaistvaid tähti, kuid see vahemik on selgelt piiritletud kahe heledatest tähtedest koosneva tähtkujuga. Seega ei ole astronoomilisest küljest olnud erilist põhjust kolmeteistkümnenda sodiaagitähtkuju tekitamiseks.

Teiseks põhjuseks võivad olla Maokandja kui tähtkuju spetsiifilised omadused: madu peetakse sümbolina väga võimsaks. Nii oli see juba Mesopotaamias, kus umbes samast ajavahemikust sodiaagi kujunemisega pärinevat ka esimene maoga seostatav tempel. Mao kui sümboli teemat on piisavalt arendatud, seetõttu vaadelgem illustratsiooniks igasuguste teooria(kes)te asemel üht praktilist juhendit John P. Prattilt:

Mida iga mormoon peaks teadma astronoomiast

Näiteks Maokandja heitleb Maoga, kes üritab jõuda kroonini, nii nagu Kristus on üle Saatanast, kes tahab saada Jumala hiilgust. Maokandja purustab ka Skorpioni pea, kes üritab teda jalga salvata, meenutades Aadamale ja Eevale antud lubadust, et Päästja [---] võib purustada mao pea ka siis, kui madu võib salvata tema põlve. (Pratt 2000)

Eelnevast lähtudes tundub, et on olemas ka võimalus, et Maokandja tähtkuju ei sobinud Rooma kõrgkihile ideoloogilistel põhjustel. Kuna astroloogia oli oma olemuselt astronoomiliste mõotmiste sissetulekuallikas, mis võimaldas saada raha täpsemaid mõõtmisi võimaldavate vahendite ehitamiseks (täpsem mõõtmine, täpsem prognoos), siis tuli ka astronoomidel sellise arvamusega leppida ja põlistada uueks sodiaagimärgiks seni olematu Kaalude tähtkuju Skorpioni sõrgade asemele.

Egiptuse sodiaagina tuntud Dendera taevakaart pärineb umbes esimesest sajandist. Dendera templist Louvre'i viidud laereljeefi peetakse Egiptuse taevakujutiseks. Tõepoolest, kujutatud tähtkujud on eripärased, Suure Vankri asemel näeme näiteks jõehobu jne. Sellel kaardil on selgelt eristuv sodiaagiring, mis olles küllalt osavalt ülejäänud kaardi konteksti sobitatud, on tegelikult juba väljakujunenud Rooma sodiaak, kõikide sodiaagi tähtkujude kujutised sarnanevad hilisematega ja Kaalud on ka olemas. 
Seega on Dendera artefakti puhul tegemist juba Egiptuse-Rooma ühtesulandatud taevakaardiga ja me ei saa rääkida selle näitel Egiptuse sodiaagist.

\section{KOKKUVÕTTEKS}

Seitse tähte taeva sõelas ja teised tuntud ütlused seitsme tähe kohta ei pea kahjuks astronoomiliselt paika. Sõelas on kas kuus tähte või palju rohkem, Suures Vankris loendab eesti rahvaastronoomia aga kaheksat tähte. Samasugune lugu on sodiaagiga, 12 tähemärki on astronoomiline fiktsioon, mida usinalt kasutatakse astroloogias. Tegelikult oligi algselt Vana-Kreeka perioodil ekliptikas 12 tähtkuju, Rooma perioodil tekitati poolkunstlikul viisil kolmeteistkümnes tähtkuju ja astroloogilises süsteemis arvati ekliptikalt välja Maokandja. Kuna astroloogia oli siiski paljudele vaatlejatele peamiseks sissetulekuallikaks, siis õiglust ja kaalukust kujutav tähtkuju polnud mitte ainult sobiv, vaid lausa vajalik horoskoopide koostamiseks. Paralleeliks tänapäeva maailmaga võib pidada olukorda, kus projektipõhise rahahanke korral ei pruugi distsipliini ajalooline järjepidevus alati kehtida ning poolkeelsed kultuurivahendajad võivad luua uusi teadmisi.

\section{KIRJANDUS}

Allen, Richard Hinckley 1963. Star Names - Their Lore and Meaning. Esmatrükk 1899. Dover Publications. http://penelope.uchicago.edu/Thayer/E/Gazetteer/ Topics/astronomy/_Texts/secondary/ALLSTA/home.html.

Andrews, Munya 2004. The seven sisters of the pleiades. Melbourne: Spinifex Press. Blunck, Jürgen 2010. Solar System Moons: Discovery and Mythology. Berliin, Heidelberg: Springer.

Evans, James; Lennart J. Berggren 2006. Geminos's Introduction to the phenomena: a translation and study of a Hellenistic Survey of Astronomy. Princeton University Press.

Fomenko, A.T.; V.V. Kalashnikov; G.V. Nosovsky 1989. When was Ptolemy's Star Catalogue in 'Almagest' Compiled in Reality? Statistical Analysis. - Acta Applicandae Mathematicae 17, pp. 203-229.

Gaedechens, Rudolph 1862. Die Antiken des fürstlich Waldeckischen Museum zu Arolsen. Göttingen.

Grotius, Hugo 1600. Syntagma arateorum. Leiden. http://www.atlascoelestis.com/ Grotius\%20021.htm.

History of Science: Libra. http://hsci.cas.ou.edu/exhibits/exhibit.php?exbgrp=3\& exbid=20\&exbpg $=61$. 
Hurt, Jakob 1899. Eesti Astronomia. Kõne Eesti Jaani koguduse Noortemeeste Seltsis 10. jaanuaril 1899. [Uustrükk: Jakob Hurt. Mida rahvamälestustest pidada: Artiklite kogumik. Tallinn: Eesti Raamat 1989, lk 91-130.]

Irby-Massie, Georgia Lynette; Paul Turquand Keyser 2002. Greek science of the Hellenistic era: a sourcebook. New York: Routledge.

Kampmann, Mihkel 1913. Kooli Lugemisraamat. Teine jagu. Kolmas täiendatud trükk. Tallinn: G. Pihlakas.

Kidd, Douglas 2004. Aratus Phaenomena. Cambridge classical texts and commentaries 34. Cambridge University press.

Kuperjanov, Andres 2003. Eesti Taevas. Uskumusi ja tõlgendusi. Tartu: Eesti Folkloori Instituut.

Kuperjanov, Andres 2005. Libamütoloogilised taevakaardid. - Mäetagused, nr 30. http://www.folklore.ee/tagused/nr30/libamyto.pdf.

Kuperjanov, Andres 2010. Sandivanker. - Mäetagused, nr 46 (ilmumas).

Mladenova, Darina 2006. Zvezdnoto nebe nad nas. Sofia: Prof. Marin Drinov.

Mooney, James 1970. Myths of the Cherokee. - Smithsonian Institution, 19th Annual Report of American Ethnology 1897-98. New York.

Müller, Karl Otfried 1978 [1844]. Introduction to a Scientific System of Mythology. Mythology. New York: Arno Press, pp. 130-145.

Pratt, John P. 2000. What Every Mormon Should Know About Astronomy. Meridian Magazine, 12 May. http://www.meridianmagazine.com.

Schaeffer, Bradley 2005. The Epoch of the Constellations on the Farnese Atlas and Their Origin in Hipparchus's Lost Catalogue. Louisiana State University. http://www.phys.lsu.edu/farnese/JHAFarneseProofs.htm, http://www.phys.lsu.edu/farnese.

Siim, Ksenia; Alleks Vallner 1967. Emakeele lugemik III klassile. Tallinn: Valgus.

Smith, William (ed.) 1870. Dictionary of Greek and Roman Antiquities. Scanned by the University of Michigan's project The Making of America. http://www.ancientlibrary.com/smith-dgra/index.html.

Studies of Occidental Constellations and Star Names to the Classical Period: An Annotated Bibliography. Web Site For Gary D. Thompson, Melton West, Australia. http://members.westnet.com.au/Gary-David-Thompson/page1127.html.

Tallqvist, Knut 1942. Plejadi-lorea. - Kalevalaseura vuosikirja 22. Helsinki. Suomalaisen Kirjallisuuden Seura, s. 118-130.

Theoi Greek mythology. Exploring Mythology in Classical Literature \& Art. Pleiades: http://www.theoi.com/Nymphe/NymphaiPleiades.html; Scorpius: http:// www.theoi.com/Ther/Skorpios.html.

Vestring, Salomo Heinrich 1998. Lexicon Esthonico Germanicum. Toimetanud Ellen Kaldjärv. Eesti Kirjandusmuuseum. Tartu. http://haldjas.folklore.ee/ r kriku/VESTRING/index.htm.

Waerden, Bartel Leendert 1974. Science awakening II: the birth of astronomy. Volume 2. Leiden: Noordhoff International Publishing. 


\section{Summary}

\section{ON TWO ASTRONOMICAL COMMON BELIEFS}

Several sayings and opinions connected with starry sky, which, from the position of popular astronomy and astronomy, might not hold true. The Great Bear (Suur Vanker) is the back part, composed of the brighter stars, of Ursa Major. The popular astronomy of many countries knows the constellation as e.g. seven brothers, the seven bright stars form a figure known as the Big Dipper, but the eighth star, a slightly weaker star named Alcor plays an important part in the Great Bear as well. Thus, in Estonian popular astronomy the Great Bear is made up of eight stars. The belief that the Pleiades has seven stars is false as well, there are either six or up to nine stars for better eyewitnesses. The phenomenon of the lost Pleiade, which is known in the popular astronomy of many countries, is observed. The 12 constellations of the zodiac are examined - the initial 12 constellations got addition during the Roman Period when the 13th constellation was invented, at the same time the constellation of Ophiuchus (the serpent-bearer), where the Sun stays for over two times longer than in Scorpio, was totally forgotten.

KEY WORDS: popular astronomy, the Great Bear, Pleiades, zodiac, early history of astronomy 